\title{
Sea state conditions for marine structures' analysis and model tests
}

\author{
Bitner-Gregersen Elzbieta M. ${ }^{1,{ }^{*}}$, Dong Sheng ${ }^{2}$, Fu Thomas ${ }^{3}$, Ma Ning ${ }^{4}$, Maisondieu Christophe ${ }^{5}$, \\ Miyake Ryuji ${ }^{6}$, Rychlik Igor ${ }^{7}$
}

${ }^{1}$ DNV GL Strateg Res \& Innovat, N-1322 Hovik, Norway.

${ }^{2}$ Ocean Univ China, Qingdao, Peoples R China.

${ }^{3}$ Off Naval Res, Arlington, VA 22217 USA.

${ }^{4}$ Shanghai Jiao Tong Univ, Shanghai 200030, Peoples R China.

${ }^{5}$ IFREMER, Brest, France.

${ }^{6}$ ClassNK, Tokyo, Japan.

${ }^{7}$ Chalmers, Dept Math Sci, S-41296 Gothenburg, Sweden.

${ }^{*}$ Corresponding author : Elzbieta M. Bitner-Gregersen, email address : elzbieta.bitner-gregersen@dnvgl.com

\begin{abstract}
:
The study reviews, based on the state-of-the-art findings, some uncertainties associated with wave data and models currently used in design and operation procedures of ship and offshore structures. Although the same basic principles prevail for hydrodynamic loads on ships and offshore structures, actual problems and methods for assessing these loads in the design and operation stage are not the same. Different wave data and models are used for specifying design and operational criteria for these two types of platforms and different uncertainties are related to them. Wave data and models used to define sea state characteristics are discussed and particular attention is given to the associated sources of uncertainties. Some weaknesses of wave input used in design and operational procedures for marine structures are pointed out. Focus is also given on uncertainties related to model tests as tank testing is an important supporting tool for design and operation. Impact of some selected uncertainties on wave description and wave loads is demonstrated by examples.
\end{abstract}

\section{Highlights}

- Definitions of uncertainties. - Establishment of sea state characteristics for marine structures' analysis and model tests. Uncertainties associated with sea state characteristics. Impact of uncertainties of sea state characteristics on model tests and design and operations of marine structures.

Keywords : Uncertainties, Wave data and models, Design and operations of marine structures 


\section{Introduction}

Enhancing safety at sea through quantification of uncertainties associated with wave description has been increasing within the shipping and offshore industries in the last decades, although the shipping industry has tended to lag behind the offshore industry. This trend has also been recognised by the ISSC (International Ship and Offshore Structures Congress) Committees I.1 Environment for some time and received special attention by the 2009, 2012 and 2015 Committees I.1 (see ISSC, 2009, 2012, 2015).

Today the demand for closer cooperation between metocean, hydrodynamic and structural groups is very high in marine engineering, and led to the initiation of the $1^{\text {st }}$ Joint Workshop UMSOS (Uncertainty Modelling for Ships and Offshore Structures) on uncertainty associated with assessment of ship and offshore structures organised by ISSC I.1 and I.2 Committees and the ITTC (International Towing Tank Conference) Sea Keeping and Ocean Engineering Committees in Rostock, 8 September 2012. A Special Issue with papers from this workshop was published in Ocean Engineering, Hirdaris et al. (2014). It was found that the joint workshop was mutually beneficial for many common interests of academia and the marine industry. Through the $1^{\text {st }}$ Joint Workshop and discussion afterward, the structural loads on ships and offshore structures in waves was chosen as the topic of the $2^{\text {nd }}$ Joint ITTC-ISSC Workshop organized by ITTC Sea Keeping Committee which took place on 30 August 2014 in Copenhagen. The workshop focused on the wave-induced motions and structural loads on ships and offshore structures, including a computational benchmark test for a large modern ship. The findings which addressed wave description presented at this workshop are reported herein.

Description of marine environment forcing conditions includes waves, wind, current, sea water level and ice. For waves a sea state is commonly defined by integrated wave parameters, such 
as significant wave height and wave period, wave spectra and/or distributions of individual wave parameters (e.g. a distribution of wave crest). Characteristics of a sea state are region and location dependent and for a limited period of time they vary in a stationary way. They represent an important input to specification of design and operational criteria of ships and offshore structures as well as for the definition of model testing programs in tanks.

Many marine structures’ loads are waves dominated therefore wave description and uncertainties associated play a central role in the assessment of loads and responses of marine structures as well as in model testing, and is also given focus herein. Although the same basic principles prevail for hydrodynamic loads on ships and offshore structures, actual problems and methods for assessing these loads in the design and operational stage are not the same. Different wave data and models are used for defining design and operational criteria for these two types of structures and different uncertainties are related to them. Model tests represent an important supporting tool for marine structures’ design and operations and for specification of model uncertainty. Wave input used in laboratory experiments will significantly influence loads and motions of marine structures being tested.

The present paper gives an overview of wave data and models defining sea states used currently for design and operations of ship and offshore structures, and discusses associated uncertainties, viewing some of them in more details. The study is illustrated by selected examples and points out weaknesses of wave input applied in assessment of loads and motions of marine structures. The aim of these investigations is to bring further awareness within the shipping and offshore industry to some of the uncertainties in wave description adopted in marine structures' assessment, using the state-of-the-art findings. 
The study does not cover smaller crafts and marine renewable energy structures as they were not addressed by the $2^{\text {nd }}$ Joint ITTC-ISSC Workshop, however, uncertainties associated with metocean description presented herein apply also to these types of structures.

The paper is organised as follows. Section 2 is dedicated to definitions of uncertainties; Section 3 shows how the sea states characteristics are established and discusses each step of this process. Uncertainties associated with wave data are addressed in Section 4 while in Section 5 assessment of sea state characteristics is given. Section 6 is dedicated to wave description in a sea state, Section 7 to model tests and in Section 8 models used in design and operational procedures of marine structures are discussed. The paper closes with conclusions, recommendations and references.

\section{Definitions of uncertainties}

Different definitions of uncertainties can be found in the literature and are applied by different scientific and engineering groups. Herein we adopt the definitions used by the structural reliability community which have been developed having Structural Reliability Analysis (SRA) in mind.

Uncertainty related to metocean description may be classified into two groups: aleatory (natural) uncertainty and epistemic (knowledge based) uncertainty. Aleatory uncertainty represents a natural randomness of a quantity, also known as intrinsic or inherent uncertainty, e.g. the variability in wave height over time. Aleatory uncertainty cannot be reduced or eliminated. Epistemic uncertainty represents errors which can be reduced by collecting more information about a considered quantity and improving the methods of measuring it. Following Bitner-Gregersen and Hagen (1990), epistemic uncertainty may be divided into: data uncertainty, statistical uncertainty, model uncertainty and climatic uncertainty. This classification is adopted herein. 
Data uncertainty is due to imperfection of an instrument used to measure a quantity, and/or a model applied for generating data. Such measurement uncertainty is usually given by a manufacturer of an instrument. It can also be evaluated by a laboratory test or full scale test (calibration). If a quantity considered is not obtained directly from the measurements but via some estimation process (or simulation), e.g. significant wave height, then the measurement uncertainty must be combined with the estimation or model uncertainty by appropriate means. Statistical uncertainty (sampling variability) is mostly related to the quality and consistency of the analysed data sample. It is for instance due to a limited number of observations of a quantity, to the existence of regions or time periods with missing data, or other sampling biases.

Model uncertainty is due to imperfections and idealisations made in physical process formulations implemented in the models as well as in choices of probability distribution types and fitting techniques applied for estimation of distribution parameters (e.g. the least squared methods, the maximum likelihood method, the method of moments). Several errors can contribute to model uncertainty. Errors can be defined as the ratio between the true quantity and the quantity as predicted by the model. A mean error value not equal to 1.0 expresses a bias whilst the standard deviation expresses the variability of the predictions by the model. Experimental tests or the average values of recognised models (or weighted models) are often used as a reference value (the true value).

Climatic uncertainty (or climatic variability) addresses the representativeness of a measured or simulated metocean variable history for the future time period in the area for which design or operational conditions need to be provided. The climate uncertainty is due to the natural variability of met-ocean climate and anthropogenic climate change, and can be regarded as a model uncertainty. 
Environmental description will be affected by all types of epistemic uncertainties but to a different degree depending on data and models applied. Quantification of uncertainty of a considered quantity requires estimation of a systematic error (bias) and precision (random error), see (Bitner-Gregersen and Hagen (1990)). It is not an easy task because the true value $\tau$, say, is usually unknown and needs to be assumed. Sparse literature systematically quantifying uncertainties can be found, although many efforts have been made in comparing different environmental data sources and models world-wide.

\section{Sea state conditions}

Wave description commonly provides information about total seas, which can be a superimposition of various wave systems, namely one wind sea and one or more swells, and is region and location dependent. It often employs a mixture of mathematical, probabilistic, empirical and statistical models. The following "decoupling” approach is commonly used. It is assumed that for a limited period of time and in a particular geographical region wave conditions vary in a stationary way called sea state. Wave conditions in a sea state can be described by means of mathematical models depending on a number of characteristic sea state parameters. Changes of sea state parameters, such as significant wave height, spectral/zerocrossing wave period and mean wave direction which vary more slowly than wave surface elevations in a sea state are modelled by means of probabilities. The final description of wave conditions for design and operations is obtained by combining the statistical/probabilistic models for sea states’ evolution (long-term statistics) with the statistical/probabilistic description of waves in a sea state (short-term statistics). Information from phase-average wave models and phase-resolving wave models is utilized often in this process. Finally, in addition to the set of integrated (global) parameters, a sea state description generally 
comprises the wave spectrum as well as information on wave directional spreading for total sea, wind sea and swell, see DNV (2014).

Statistical description of sea states classically required for design of marine structures and management of marine operations is based on the analysis of long duration time series of wave data. To establish such a long-term statistical description of sea states, visual observations, wave measurements (in-situ, remote sensing) and hindcast datasets can be used. For a limited period of time and in a particular geographical region wave conditions vary in a stationary way. In design it is commonly assumed that a sea state remains stationary for 3-6 hours. However, in coastal areas where wave-current interaction cannot be neglected and for the design of marine energy converters, strongly affected by sea states variability, a one-hour time step becomes a standard.

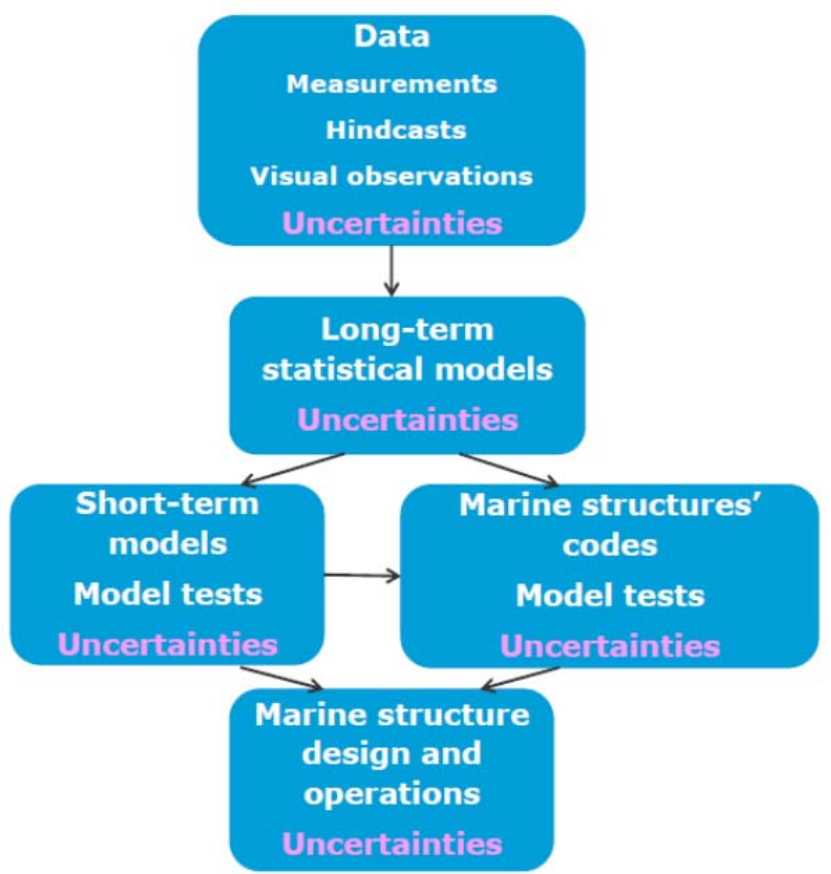

Fig. 1. Flowchart showing how sea state characteristics are specified. 
These long-term statistics can be used both for fatigue aging analysis and for extrapolation of extreme values over a given return period not only for structural design exposed to unrestricted weather conditions but also for design criteria for structural parts exposed to weather restricted conditions, such as e.g. for LNG terminals criteria for the connecting mooring lines and fenders; see Hagen et al. (2015). When planning and carrying out marine operations both a threshold for significant wave height (and/or associated metocean parameters) and a required weather window represent important characteristics which are derived from long-term statistics (Bitner-Gregersen, 2015).

Long-term statistics provide also input to description of wave conditions in a sea state and to model tests, which are supporting design and operation process of marine structures, as illustrated in the flowchart shown in Figure 1. Each step in the flowchart is affected by associated uncertainties and the relevant ones need to be accounted for in assessment of marine structures' loads and motions to obtain satisfactory results.

\section{Uncertainties related to datasets}

\section{$4.1 \quad$ Visual Observations}

Visual observations of waves collected from ships in normal service and summarized in the British Maritime Technology Global Wave Statistics (GWS) atlas (BMT, 1986) are used by the maritime industry. The atlas includes scatter tables of significant wave height and zerocrossing wave period. The data does not include any information about wave spectra. The use of visual observations requires an appropriate calibration versus accurate measurements of the wave characteristics. BMT (1986) compared the GWS marginal distributions for wave heights and wave periods with instrumental Shipborne Wave Recorder and National Oceanic and Atmospheric Administration (NOAA) buoy data for different locations and concluded that the wave heights and periods for which statistics were given corresponded to measured 
values. However, the accuracy of the GWS data has been questioned in the literature since the 1990s, especially concerning the wave period as discussed, e.g. by Wing and Johnson (2010), Bitner-Gregersen et al. (2014b, 2014d). Note also that the GWS Atlas was published in 1986 thus the last 30 years, when many severe storms occurred, is missing.

\subsection{In-situ measurements}

Wave buoys, wave staff, radars, lasers, LASAR (an array of lasers) and step gauge remain the most widely used devices for in-situ measurements. Also use of Lidar observations and satellite data is growing in engineering applications. Wave data are affected by measurement, statistical (sampling variability) and model uncertainties Bitner-Gregersen et al. (2014a, 2014b) which are not fully quantified today. A question getting increasing attention in the last years is: Are these in-situ measurements actually ground truth? This question was also raised during the $13^{\text {th }}$ International Workshop on Wave Hindcasting and Forecasting and $4^{\text {th }}$ Coastal Hazards Workshop which took place in Banff, Canada (Jensen et al., 2013), but a final answer still does not exist.

Specific issues for the most common wave measurement systems include:

- Buoy - Significant wave height $H_{s}$ is mainly derived from the vertical motion of the wave buoys and uncertainties are related to the actual ability of the float to accurately follow the free surface, especially in steep waves when non-linear effects are present and coupling with the mooring line may alter buoy’s dynamics (the buoy may "cut" the top of the wave off). When considering buoys equipped with accelerometers, filtering induced by the signal processing may also induce linearization of the response. Major uncertainties are related to the estimation of wave direction and directional spreading. Uncertainties associated with the various methods proposed for the estimation of the directional distribution function are not well known and still to be 
investigated. Whilst they likely get the dominant wave direction, they will tend to smear energy in a given frequency band if there are multiple systems that propagate at similar headings. Accuracy on directions estimate is dependent on the number of degrees of freedom and on the methods used to derive the 2D spectrum. Three DOF buoys have difficulty resolving directional wave energy due to the poor directional resolution. Additionally, methods used for re-composition of the directional function (Kahma et al., 2005), (Saulnier et al., 2011) may induce alterations of the directional distributions. Parametric methods, introducing functions such as $\cos ^{2 s}$ will impose a particular shape to the distribution whilst the use of statistical methods such as the Maximum Entropy Methods (MEM) (Krogstad et al., 2004), (Benoit et al., 1997) may introduce artificial secondary peaks. It needs to be noted that some non-linearities that would appear in an Eulerian frame of reference are not seen in the Lagrangian one of a buoy (Prevosto et al., 2000). For random Lagrange waves see also Lindgren and Prevosto (2015).

- X-Band Radar - The dominant source of uncertainty for these systems comes from the calibration. If there is an assumed linear relationship between $H_{s}$ and the square of SNR (Signal-to-Noise Ratio), then an issue is how is the spread in the fit applied to the measured $H_{\mathrm{s}}$ data? A universal uncertainty cannot be applied for all radars since it is dependent on the actual data used during calibration. (Nieto-Borge et al., 2008) shows a typical calibration curve. At a SNR of 1.5 the $H_{s}$ values ranged from $2.5-4 \mathrm{~m}$. So while period and direction may be easily obtained from these systems, accurate $H_{s}$ measurements are still a topic for further research, Fu et al. (2011), Nielsen and Stredulinsky (2012). An X-band (8.0-12.0 GHz) radar mounted with a 360-degree field of view is shown in Figure 2. 


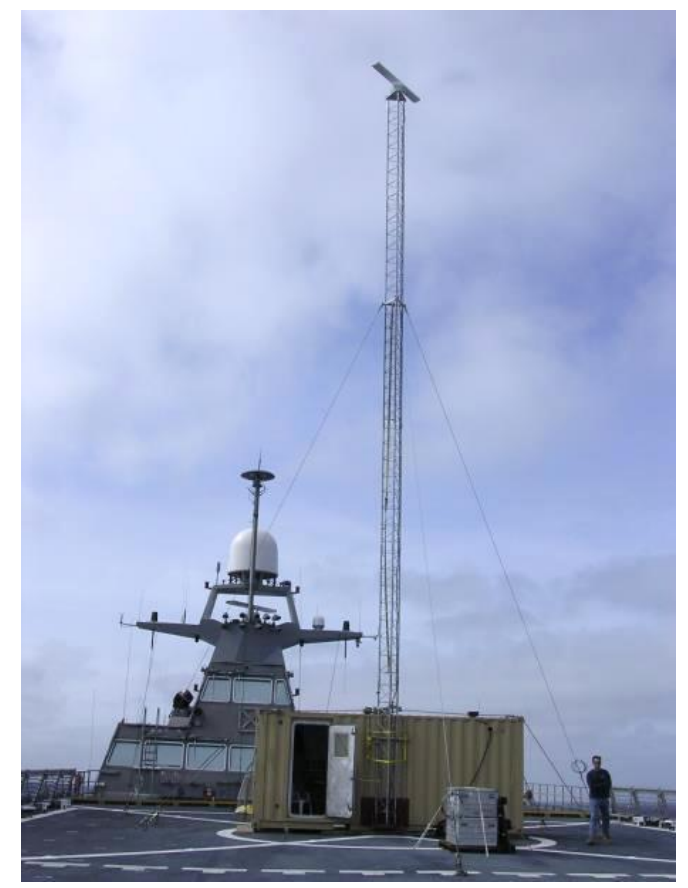

Fig. 2. Tower mounted X-Band (9410 MHz) wave radar temporarily installed onboard the U.S. Navy's FSF-1, Sea Fighter, to measure the wave field during sea trial.

- HF-Radar -These radars typically range in frequency from 3-30 MHz, with some systems reaching $50 \mathrm{MHz}$ and are being more and more common in coastal areas, however, there is also an issue related to their calibration. Work continues on understanding the limitations of HF radar measurements. In particular, Wyatt et al. (2011) identify aspects of measurements made at three coastal stations that require further improvement. These include modifications to the underlying theory, particularly in high sea states, identification and removal of ships and interference from the radar signals before wave processing and some form of partitioning to remove these from the wave spectrum. The need to match the radio frequency to the expected wave peak frequency and wave height range, with lower radio frequencies performing better at higher wave heights and lower peak frequencies and vice versa, is also demonstrated. A shore-based HF radar is shown in Figure 3. 




Fig. 3. - High frequency (HF) radar systems measure the speed and direction of ocean surface currents in near real time.

- Lidar - Fixed point measurements need to consider instrumentation accuracy in the range estimate provided by the instrument. The absorption of water also needs to be accounted for. For free surfaces with low void fraction this error is likely less than any uncertainty in the long range resolution. Typical range resolutions are around +/- 2.5 cm and thus would likely only be of concern in very low sea states. A typical commercial Lidar distance sensor is shown in Figure 4.



Fig. 4. Commercially available Lidar distance sensor.

Most in-situ wave recordings take place in coastal areas. Locations where high quality in-situ data are available are sparsely distributed, since buoy and platform data are geographically limited. However, measured wave data either locally or remotely remain important for 
development, calibration, and validation of numerical wave models used for generating hindcasts, particularly in coastal areas due to shallow-water aspects of wave dynamics. The measured data are also important for providing description of individual wave characteristics in the open ocean and coastal waters as well as for validation of phase-resolved wave models. Therefore the process of improving accuracy of wave instruments and extension of in-situ measurements to deep water locations (see e.g. Waseda et al. 2014) needs to continue.

\subsection{Remote sensing}

Even though satellite observations offer global coverage, they suffer from temporal intermittency, with return periods between 10 days and about one month, and spatial scarcity with intertraces ranging between about $100 \mathrm{~km}$ and $300 \mathrm{~km}$ depending on the mission, making estimation of long-term distributions and extreme analysis difficult. However, remote sensing data, mostly derived from altimeters and synthetic aperture radars (SAR) is more and more in use for design applications, as a complement to sea states in-situ measurement data.

- Altimeters - Apart from errors possibly induced by data processing and noise reduction, uncertainty on significant wave height $H_{s}$ derived from altimeters measurement is related to the calibration process against buoys and inter-calibrations between sensors embarked on-board the various successive missions (Queffeulou, 2013). However, significant wave height derived from altimeter data is usually considered of good quality and is also used for calibration/validation of hindcast models.

- SAR - Mainly because of their low cut-off frequency, Synthetic Aperture Radars are no good candidates for assessment of the significant wave height, especially when considering wind-sea dominated or complex sea-states. However information they 
provide on spectral and directional characteristics of swells may be of interest, for instance for local in-situ datasets validation (Collard et al., 2005).

Accuracy of satellite data is discussed in details by ISSC (2009).

Remote sensing, apart from providing important metocean characteristics, has the ability to offer assessment of wave trains propagation across oceanic basins (see e.g. Young et al., 2013). As the coverage offered by satellite altimeters and space-borne Synthetic Aperture Radars is still sparse and spectrally limited utilization of multiple mission satellite observations is strongly encouraged. Further, investigations aiming at providing satellite wave products for users need to continue as satellite observations represent large potential for the marine industry.

\subsection{Hindcast data}

Numerical wave models used for forecasting or building hindcast data bases are under constant evolution, see e.g. ISSC (2012, 2015). The WAM model and the WAVEWATCHIII model are the most generalized and tested wave prediction models used for both hindcasting and forecasting purposes in deep water. Although both WAM and WAVEWATCH-III are 3rd generation (3G) wave models, they now differ in a number of physical and numerical aspects and may give different predictions. This is an indication that a single "best” solution has not yet been accepted, Cavaleri et al. (2007). In shallow water the code SWAN is commonly utilized.

Ability of wave models to generate high quality hindcast datasets has largely improved over the last decade, thanks to new developments in both parameterization, introducing more consistent description of the physics based on observations, and numerical choices (Roland and Ardhuin, 2014). Hindcast data quality is usually validated against in-situ or remote sensing data (Boudière et al., 2013) and generally only significant wave height and peak or 
mean period and peak or mean direction are considered, assessing standard metric errors such as mean bias, centered root mean square error (CRMSE) and scatter index (S.I.). It should be noted that such validation conducted on the sole global parameters do not provide a full validation of the data as it doesn’t account for the quality and accuracy of the spectral and directional distribution of the wave energy, which is also of prime importance for design and fatigue studies, especially when considering areas and sites where complex sea states propagate. Such lack of validation on the spectral and directional distribution of the energy certainly represents a major source of uncertainty and standard validation methods are yet to be defined.

Global parameters bias correction can be easily performed, introducing a mean off-set.

However, such a corrected hindcast even though unbiased on average still can be corrupted by other types of errors, which may introduce a bias in the estimated return values of extreme sea states.

In the extra-tropics these hindcasts can be expected to provide good estimates of wave climate, especially for the highest waves, whereas ship observations of the highest waves are notoriously unreliable, and may be subject to some fair-weather bias. Hindcast models are somewhat less reliable in the tropics, however tropical storms waves are identified as less extreme and usually do not define the design criteria for a sailing ship. However they will affect offshore structural design.

Apart from assumptions adopted in the formulations describing the physics, quality of wave model hindcasts can be affected by the model resolution, in both space and time. A coarse resolution of a wave model may give up to a few meters lower significant wave height $\left(H_{m 0}\right)$ extremes than a high resolution. Figure 5 shows the distribution of $H_{m 0}$ in one location in the North Atlantic obtained from the ERA-Interim database having a resolution of ca. 80 km x 80 km (data are sampled every 6 hour) and the NORA10 database having a resolution of $10 \mathrm{~km} \mathrm{x}$ 
$10 \mathrm{~km}$ (data are sampled every 3 hour). The data from one North Atlantic location have been fitted by a 3-parameter Weibull distribution. The estimated from the fit 100-year extreme is, $H_{m 0}=19.5 \mathrm{~m}$ for the NORA10 data and $H_{m 0 \approx} 16.5 \mathrm{~m}$ for the ERA-interim data. Further, high resolution of wave model may give up to $40 \%$ higher wave steepness compared to the coarse resolution, Bitner-Gregersen and Toffoli (2015).

a)

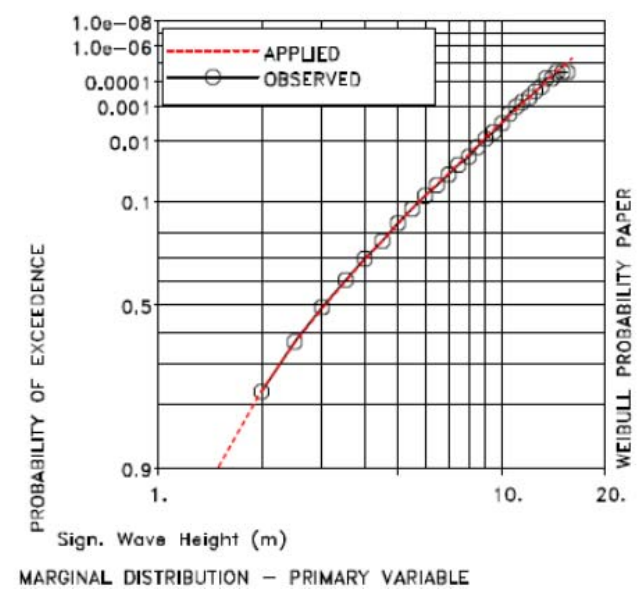

b)



Fig. 5. Empirical and fitted distributions of $H_{m 0}$ for total sea in the North Atlantic location. a) ERA-Interim data; b) NORA10 data.

Finally, quality of the forcing fields used as input when running the wave models represents another source of uncertainties. For instance, it was shown (Ardhuin et al., 2012) that including currents in a wave model could result in error reductions by up to $30 \%$ on the evolution of the significant wave height; even at locations where currents are relatively weak but which are located down-wave of strong current gradients that cause large refraction effects. Quality of wind forcing fields may also vary in time and regional biases have been reported (Rascle and Ardhuin, 2013; Chawla et al., 2013). Additionally, validation of the wind highest speed range is usually considered less reliable. 
However, wave hindcast datasets, offering long time series of global parameters and complete spectral information on refined grids at global and regional scales are considered the choice data sets for development of design and operation criteria of marine structures, providing that prior validation against in-situ and satellite data has been properly conducted. Uncertainties involved in hindcasts need to be in focus in engineering applications and carefully considered on a case by case basis.

Due to development of computers wave frequency-directional spectra have started to be archived by some met-offices opening new possibilities for environmental modelling as well as design and marine operations. Utilization of this information by the marine industry is strongly recommended. For instance, when investigating the response of an offshore structure, spectral hindcast databases, composed of time series of wave spectra, whenever available, should be used preferably to sets of spectra built from analytical formulations such as JONSWAP (Hasselman et al., 1973), because of the inability of such theoretical unimodal forms, characterized by a single set of three global parameters, to correctly account for the spectral distribution of the wave energy in the case of complex sea-states (Maisondieu and Le Boulluec, 2015).

\section{Assessment of sea state characteristics}

Whether the dataset used for long-term assessment was obtained from in-situ measurement, remote sensing, hindcast model or visual observations, additional uncertainty can raise from the methods used for estimation of the global parameters.

Significant wave height $H_{s}$ and spectral (or zero-crossing) wave period $T_{p}\left(T_{z}\right)$ represent important parameters for design and operations of ships and offshore structures. They are used for validation of wave models, wave climate studies and calculations of extremes, as well as for weather forecasting purposes. Whether significant wave height $H_{s}$ is determined, 
using directly wave-by-wave statistics of surface elevation time series $\left(H_{1 / 3}\right), 4 *$ standard deviation (std) of the free surface time series or via calculation of the zeroth moment of the spectrum $\left(M_{0}\right)$, the statistical uncertainty that should be accounted for is present (BitnerGregersen and Hagen, 1990; Bitner-Gregersen and Magnusson, 2014). Also $H_{s}$ computed via $4 *$ std or by $4 * \operatorname{sqrt}\left(M_{0}\right)$ won't necessarily be equal due to windowing/overlapping of segments during calculation of the spectrum and will depend on the spectrum adopted (e.g. an empirical, the JONSWAP, 1973, or Pierson-Moskowitz, 1964). Each measuring system has a specific frequency bandwidth it is able to measure, and no single system can measure the entire wave spectrum. Further, $H_{s}$ computed via $4 *$ std of surface elevation is only equal to the one calculated via $4^{*} \operatorname{sqrt}\left(M_{0}\right)$ if the sea surface is a narrow-banded Gaussian process (see Cartwright and Longuet-Higgins, 1956).

Additionally, whenever observations of the ocean wave environment are made, the questions of stationarity and ergodicity need to be addressed.

Variability of the integrated wave parameters in time are approximated by long-distributions from which return period extremes are estimated. These return period estimates will be affected by data uncertainty, model uncertainty (due to an adopted distribution and procedure for fitting distribution parameters, climate uncertainty associated with the number of years considered) and statistical uncertainty, if the number of data is limited. Definition of sea states hazardousness clearly depends on the particular application, e.g. steep sea states are dangerous for capsizing of small vessels, they are also critical for parametric roll.

Research efforts regarding refining models and estimation procedures of the long-term sea description continues, given particular focus to the associated uncertainties; see e.g. ISSC (2009, 2012, 2015). Effects associated with the variability of the probability of extremes as a function of season and of direction as well as in space have been pointed out recently, Feld 
(2014), Jonathan et al. (2014), Ewans and Jonathan (2014). There are statistically significant differences between return values for different directions and seasons and they vary in space. In Mao and Rychlik (2012) the spatio-temporal model of significant wave height due to Baxevani et al. (2008) combined with a transformed Gaussian model was used to estimate extreme ship response when sailing on a North Atlantic route.

Implementation of seasonality, spatial and non-stationary statistics in design needs still further investigations and attention to these effects should be given.

When developing design and operational criteria for ships and offshore structures joint longterm models of significant wave height and wave period are often used for calculation of return values. They are particularly required for a level III reliability analysis (Madsen et al., 1986). Utilisation of a joint fit for fatigue calculations is shown by Olagnon and Guédé (2010). A review of joint long-term probabilities can be found in Bitner-Gregersen (2012, 2015). Various joint fits to wave data can be found in the literature. Some of them utilise complete probabilistic information obtained from simultaneous observations of the environmental variables as e.g., the Conditional Modelling Approach (CMA), e.g. Bitner-Gregersen ( 2012). If the available information about the simultaneously occurring variables is limited to the marginal distributions and the mutual correlation, then, as shown by Der Kiuregihan and Liu (1986), the Nataf (1962) model can be used. The Nataf model should be used with care because it can give biased results, Bitner-Gregersen and Hagen (1999). Further, joint fits may utilise all data from long series of regular observations, or be based on the observations over some threshold level (e.g. POT data). The global approach includes correlation among observations which in the event model maybe nearly independent. For locations when two or more wave systems (wind sea and swell or several swells) are present joint probabilities need to account for it not to obtain biased results, as suggested e.g. by Olagnon and Guédé (2010), Kpogo-Nuwoklo et al. (2014), Bitner-Gregersen (2012). Olagnon and Guédé (2010) show 
how to model several swell components. Modelling of two or more wave systems and specification of uncertainties related to different approaches still need further research. Recently attention has been given to the use of multivariate copulas in establishment of joint probabilities, e.g. Tao et al. (2013a, 2013b), Dong et al. (2013a, 2013b). Note that copula models do not utilize the complete probabilistic information obtained from simultaneous observations. A systemic comparison of approaches applied today for description of joint probabilities, including copulas models, using data from several ocean regions is still lacking and needs attention.

SAR (Synthetic Aperture Radars) images and hindcasts provide wave spectra. Wave spectra can also be derived from in-situ measurements. SAR spectra do not include waves with a wave period shorter than about 10 to 11 seconds therefore are primarily applicable for description of swell. Wave hindcast spectra include both wind-sea and swell components but an adopted procedure for partitioning wind-sea and swell in the wave spectra will affect integrated parameters derived from them such as $H_{m 0}$ and $T_{p} / T_{z}$ for wind sea and swell, which eventually will impact return values (Bitner-Gregersen, 2015). Empirical formulations of wave spectra are used extensively in offshore engineering such as modified versions of the Pierson-Moskowitz, PM, (1964) spectrum and the JONSWAP spectrum (Hasselman et al., 1973) for unimodal conditions (one wave system), and the Ochi-Hubble (1976) and Torsethaugen (1993, 1996) spectrum for bimodal sea states (DNV, 2014). The two peak spectrum due to Guedes Soares (1984) can also be used. The maritime industry has traditionally used the PM spectrum (IACS, 2000) although recently the JONSWAP spectrum and a double peak spectrum have been applied, particularly for evaluation of ship operational criteria. There is still uncertainty about the form of the decay in the high frequency tail - the (modified) PM and JONSWAP formulae have an $f^{5}$ tail decay, while field data and the theory show an $f^{4}$ tail decay, Philips (1958, 1985), Kitaigorodskii (1983). As shown by 
Torsethaugen (1996) based on an analysis of field data the high frequency tail of a wave spectrum is changing with significant wave height, but the topic still needs further investigations. Use of $f^{5}$ or $f^{4}$ may have significant consequences for marine structures' loads and responses if they are sensitive to the high frequency spectrum tail (see e.g. BitnerGregersen et al., 1992).

Firm conclusions regarding modelling of the swell spectrum have not been reached yet. Recent investigations carried out have shown that the swell spectrum have a triangular or lognormal shape (Forristall et al., 2013). Sampling variability makes it difficult to distinguish between those shapes or JONSWAP or Gaussian forms suggested by other authors.

Sea state characteristics provide input to short-term wave description (phase-resolving models, statistical distributions) and model tests which are discussed in the following sections.

\section{Wave description in a sea state}

Wave models in deep and finite water depth describing short-term variations of water surface in a sea state may be categorized into the following classes: linear wave models, Boussinesq, Kadomtsev-Petviashvili (KP) and Korteweg-de Vries (KdV) models, second order wave models, and higher-order wave models. For extreme waves in extremely shallow water, the Boussinesq equation model (or KdV model, or its generalisation the KP equation) or its higher order extension is usually adopted with a relevant non-dimensional number, say Ursell number (ratio of wavelength, wave amplitude and water depth). For intermediate water depths the $2^{\text {nd }}$ order shallow water theory is applicable whilst in deep water the $2^{\text {nd }}$ order deep water theory may be applied. Higher order theories are needed for extraordinarily steep sea states to capture abnormal waves, also called freak or rogue waves. An example of an abnormal wave, being much higher and steeper than the surrounding waves in the record, is shown in Figure 6. 




Fig. 6. The wave profile time series during the Andrea storm as measured by the laser within 20 min with $5 \mathrm{~Hz}$ sampling frequency at the Ekofisk field 9 November 2007, after Magnusson and Donelan (2013).

Extreme and rogue waves have been studied extensively in the past two decades, for a review see e.g. ISSC (2012, 2015). The investigations have been conducted theoretically, numerically, experimentally and based on field data. The occurrence of rogue waves, their generation mechanism, and detailed dynamic properties are now becoming clear. Three important review publications have been issued recently: Dysthe et al. (2008), Kharif et al. (2009) and Osborne (2010), gathering significant findings within the field of extreme and rogue waves. The recent state-of-the-art review on mechanisms responsible for generating these waves can be found in Onorato et al, (2013); see also Bitner-Gregersen et al. (2014c). For detail studies of some mechanisms generating these waves see, e.g. Onorato et al, (2006a, 2006b), Hu et al. (2010a, 2010b), Hu and Ma (2011), Cavaleri et al. (2012), Bitner-Gregersen and Toffoli (2014). These mechanisms can be classified as follows: linear Fourier superposition (frequency or angular linear focussing), wave-current interactions, crossing seas, quasi-resonance nonlinear interactions (modulational instability), shallow water effects and wind.

As demonstrated in the EC EXTREME SEAS project (EXTREME SEAS, 2013), the numerical codes used satisfactorily for the description of rogue waves include: NLS (NonLinear Schrödinger) equation [2D, 3D], Dysthe model [2D, 3D], HOSM (High-Order 
Spectral Method) [2D, 3D] and Conformal Method [2D]. These codes have been applied and enhanced in EXTREME SEAS and validated with field and laboratory data.

Further, several field observations including rogue waves have been recorded in the different parts of the oceans showing that these waves can occur in low, intermediate and high sea states; e.g. Haver and Anderson (2000), Nikolkina and Didenkulova (2012), Didenkulova et al. (2013), Magnusson and Donelan (2013), Waseda et al. (2009 a, 2009b, 2011, 2014), Wang et al. (2014), and Christou and Ewans (2014).

Most attention has been given in the last decade to quasi-resonance nonlinear interactions (modulational instability), one of the mechanisms responsible for generating rogue waves in deep water which can be identified by the Benjamin Feir Index, BFI, (see e.g. Onorato et al. 2006a, 2013). However, Toffoli et al. (2013) showed, based on experimental observations supported by numerical simulations, that a carrier wave becomes modulationally unstable even for relative water depths $k_{p} h<1.36$ (with $k$ the wavenumber of the plane wave and $h$ the water depth), when it is perturbed by appropriate oblique disturbances.

In current design practice (see Section 5) the wave spectrum is traditionally assumed to be constant and is usually modelled in terms of frequency spectra such as Pierson-Moskowitz, JONSWAP, Torsethaugen, or Ochi, with a unimodal directional energy spreading function, such as $\cos ^{N}(\theta)$ (see e.g. DNV RP C-20014). However, numerical experiments and field measurements have demonstrated that the wave spectrum evolves as a result of non-linear effects. For example, a frequency spectrum may experience a broadening, as well as a downshift, of the spectral peak as a result of modulational instability. In the directional space, it has been shown that that nonlinear interactions spread energy outwards from the spectral peak along two characteristic directions, in qualitative agreement with a theoretical model proposed by Longuet-Higgins (1976). As a result, the directional distribution develops a 
bimodal form as the wave field evolves. These effects have also been found in numerical simulations of NLS equations (Dysthe et al., 2003) and by HOSM simulations (Toffoli et al, 2010). The bimodal shape of the directional distribution was also shown in field data by Ewans (1998), and resulted in a bimodal distribution being proposed that is currently used in the design of offshore structures.

The presence of rogue waves has an impact on statistics of surface elevation and associated wave parameters such as wave height and wave crest (Toffoli and Bitner-Gregersen, 2011) which are important wave characteristics for engineering applications. It needs to be noted that the effect of modulational instability is gradually suppressed when the wave energy spreading increases and the second order wave theory is adequate to describe the statistical behaviour of ocean waves up to a particular probability level; for the review see ISSC (2012). In changing climate growth of storm activity (intensity, duration and fetch) and changes of storm tracks in some ocean regions may result in secondary effects such as increased frequency of occurrence of rogue waves, see e.g. Bitner-Gregersen and Toffoli (2014, 2015).

It needs to be mentioned that there exist abnormal waves created by the displacement of an atmospheric pressure front/anomaly at the shallow water called meteo-tsunamis (Monserrat et al., 2006; Haslett and Bryant, 2009). Small crafts seem to be often hit by these waves.

\section{Model tests}

Wave tank testing has been used for many years as part of the standard design procedure, for the purpose of both numerical models validation and characterization of the loading and dynamic response of marine structures. Model testing is classically conducted in wave tanks on models at reduced scale, in either harmonic wave, so as to assess the frequency response of the structure, in irregular waves with the objective of assessing the response of the structure to 
conditions corresponding to real or representative sea states, or considering high and steep waves or wave packets for assessment of response to waves with rare occurrence.

The ability of reproducing actual sea states in a wave tank can be somehow limited because of both the chosen scaling law and the intrinsic limitations of the basin and the wave generator it is equipped with. Such limitations may induce alteration of the actually reproduced sea states, hence uncertainties on the loads and responses of the tested structure.

When testing in waves and investigated loads are dominated by gravity forces, scaling is conducted according to Froude law: $F_{r}=\frac{U}{\sqrt{g L}}$ so that, in order to respect similitude, time is reduced as $\sqrt{E}$ where $E$ is the length scaling factor. Hence the bandwidth of the reduced wave spectrum may be lying out of the bounds of the wave maker's bandwidth, inducing a frequency cut-off, usually in the high frequency tail of the generated wave spectrum. Additional limitations in the statistical description of wave spectra in wave tanks may be induced by the chosen discretization parameters, both the number of components and the frequency step (Mc Combes et al., 2010a, 2010b). In the case of wave tanks equipped with multi-directional wave-makers, reproducibility of directional properties of the wave spectrum can also be limited in both mean direction and spreading depending on the control methods (Schäffer and Steenberg, 2003) and geometric dimensions of the wave tank itself.

As a matter of fact, the size of the basin maybe a limiting factor in the ability to reproduce realistic sea states as reflections on the walls of the tank can never be totally avoided, yielding a strong limitation in the duration of the time series of waves to be generated. Hence, one of the main issues when performing experiments is the reduction of the sampling variability, the uncertainty due to limited number of data.

Sampling variability is an epistemic uncertainty and can be reduced contrarily to the intrinsic uncertainty on sea surface elevation which is always present. For stationary meteorological 
conditions, due to randomness of sea surface, wave parameters derived from a wave record will depend on which part of the wave record is used in the analysis as well as on the length of the wave record (Bitner-Gregersen and Hagen, 1990; Bitner-Gregersen and Magnusson, 2014). An error introduced by the limited length of a wave record is an epistemic uncertainty and can be reduced by increasing duration of wave measurements/numerical simulations. Ideally a wave record should be infinite to eliminate sampling variability. Numerical simulations of water surface represent a good support to field and model tests as they allow reducing sampling variability by increasing duration of simulations when wave input is kept constant and intrinsic variability is accounted for. This is more difficult in nature, where stationarity of sea states is an issue, and in model tests due to the costs associated with repeated model test runs.

Model tests need to be repeated a sufficient number of times to reduce sampling variability otherwise biased results may be obtained, no matter how accurate the instrumentation used in the experiment, see Johnson (2004), Guo et al. (2013), Bitner-Gregersen et al. (2014b); Bitner-Gregersen and Magnusson (2014). Inaccuracy introduced in test results due to the limited data can be accounted for in load and response analysis in terms of distribution functions or standard deviations. The bootstrapping technique can be used to establish these uncertainties.

It needs also to be mentioned that to reflect intrinsic variability of linear and nonlinear numerical simulations of surface elevation as well as waves generated in model basins, wave models and laboratory wave makers have to account for random amplitude and phase of a wave field. Further, modulational instability occur typically after 10-30 wave lengths from a wave maker thus the scale of model tests should be considered carefully to be able to generate abnormal waves in a basin (Onorato et al., 2004). 
Introduction of very steep waves such as rogue waves in tank testing procedures (see Figure 3) is rather new, even though research on that topic has been conducted for many years.

Recently extensive laboratory tests of extreme and rogue waves have been carried out by two research projects, EC EXTREME SEAS and ShorCresT JIP (continuation of the CresT JIP), and the EC-Hydralab IV program. Some tests of the EC-Hydralab IV program were utilised by EXTREME SEAS.

In EXTREME SEAS (2009-2013) model tests have been carried out in the tank of Technische Universität Berlin (TUB) and the Spanish basin Canal de Experiencias Hidrodinamicas de El Pardo (CEHIPAR). In addition the project utilized model tests data from experiments carried out world-wide in which the project partners had participated. The first phase of the tests consisted of generating the target deterministic wave sequences with inserted extraordinarily large waves and irregular waves with rogue waves (unidirectional and with varying directional spreading). Measurements, apart from water surface, also included kinematic characteristics of these waves. In the second phase of the model tests ship behaviour in extreme and rogue waves have been studied. Four ships have been investigated by the project: the LNG Tanker, Product/Chemical Tanker, Cruise Ship and Large Container Ship. The ships were instrumented so as to measure motions and wave induced loads. Both extraordinary rogue waves: the Draupner wave and the Andrea wave have been reproduced in the tank testing, the Draupner wave in the TUB tank while the Andrea wave (see Figure 3) in the CEHIPAR basin. At the Technical University of Berlin breather solutions of the Nonlinear Schrödinger (NLS) equation have been successfully produced with help of the University of Torino and used for the first time in sea-keeping tests Clauss et al. (2012), opening up new perspectives in the methodology of examining offshore structures and ships against rogue waves. 
Model tests in the CresT (2009-2011) and ShortCresT (2011-2014) JIP projects have been carried out in the MARIN and Imperial College basins and were addressing offshore structures. The ShortCresT investigations included long crested and short crested waves (short crested waves at different scales) and frequency spectra of field and basin waves. Buchner and Forristal (2012) observed in ShortCresT that short crested basin waves and field waves showed very similar behaviour. The final results of the CresT project are summarized in Buchner et al. (2011) while of the ShortCresT project in Hening et al. (2015). The Crest and ShortCresT investigations of nonlinear waves in the basin are generally confirming the findings of EXTREME SEAS, wave directionality plays an important role in generation of rogue waves.

Some aspects of uncertainties related to model tests can also be found in Qui et al. (2014).

\section{Design and marine operations}

\subsection{General}

New designs and operational decisions must be assessed/made according to recognised codes and standards, on the definition of which the responsible authority, perhaps a classification society or the user himself, will depend. To achieve recognition, an environment parameter's climatology must be demonstrated to be robust and of adequate accuracy, and consequently such codes and standards may lag behind the state-of-the-art. Not only information about the state-of-the-art wave data and models is important in this process but also about associated uncertainties.

Ships experience varying wave climate during a sailing route. Unlike ship structures, offshore structures normally operate at fixed locations and often represent a unique design. Therefore although the same basic principles prevail for hydrodynamic loads on ships and 
offshore structures, actual problems and methods for assessing these loads in the design and operation stage are not the same. Additionally different wave data and models are used for specifying design and operational criteria for these two types of structures.

A design process for marine structures requires a check for ultimate loads but also for fatigue damage. Operational criteria include not only metocean criteria related to daily marine operations but also specification of weather conditions for deployment and installation of offshore structures.

At present climate change and rogue waves are not explicitly included in classification societies’ rules and offshore standards due to a lack of sufficient knowledge about uncertainties associated with climate change projections and a full consensus reached about probability of occurrence of rogue waves. Significant uncertainties associated with climate change projections still remain and further research is needed to quantify them and to agree on an approach allowing accounting for them in design. Further, open access to field wave data, including rogue waves, and more detailed information about wave conditions when marine accidents occur in accident databases are also called for to conclude about the probability of occurrence of rogue waves. However, both rogue waves and climate change are under discussion for possible implementation in the revised version of the Norwegian standard NORSOK (20007). It is worth to mentioning that the oil company STATOIL has already introduced an internal requirement accounting in a simplified way for rogue waves, see ISSC (2013, 2015).

Rogue waves will impact both local and global loads as well as fatigue damage. More investigations quantifying effects of these abnormal waves on loads, motions and fatigue damage are still needed. 
Use of the CFD methodology in analysis of marine structures is increasing within the shipping and offshore industry requiring a proper description of sea states as well as extreme and very steep waves.

\subsection{Ships}

The majority of ocean-going ships are currently designed so as to withstand the North Atlantic wave environment, which is regarded as the most severe. It is interesting to note that recent investigations of global wind and wave conditions are confirming the latter, see Cardone and Cox (2011), Cardone et al. (2014).

Visual observations of waves collected from ships in normal service and summarized in the British Maritime Technology Global Wave Statistics (GWS) atlas (BMT, 1986) are used for ship design and operations. The average wave climate of four ocean areas in the North Atlantic, with some correction introduced due to inaccuracy of zero-crossing wave period Bitner-Gregersen et al. (1995), is recommended by the International Association of Classification Societies (IACS 2000) for ship design.

The visual BMT data represent a sufficiently long observation history to provide reliable global climatic statistics over most of the global ocean. Observations of wave height, period, and direction have been collected from ships in normal service all over the world since 1949, and are made in accordance with guidance notes from the World Meteorological Organisation (WMO, 2001; WMO, 2003). These data include some bad weather avoidance as ships tend to avoid sailing into storms; today many ships receive weather forecast from meteorological offices. Thus this database is probably biased towards lower wave heights, see e.g. BitnerGregersen et al., (2014d). As mentioned in Section 4.1 the GWS Atlas was published in 1986 and the missing last 30 years data seem to to have impact on extreme values of significant wave height. The 100-year $H_{s}$ reported by Grigorieva and Gulev (2006) using visual observations up to 2006 is beyond 18-19 m in the North Atlantic, ca. 2 m higher compared to 
the value given by the IACS scatter diagram, but the results are affected by an approach adopted to calculate the $H_{s}$ extremes. Further, the mean $H_{s}$ is also higher.

Apart from uncertainties associated with the GWS data discussed in Section 4 and the missing last 30 years, the limitation of these data is due to a lack of information about directional wave spectrum, as pointed out by Wing and Johnson (2010), and Bitner-Gregersen et al., 2014b). Wing and Johnson (2010) have shown that wave directionality have quite an unpredictable effect on the long-term ship motions and loads.

It needs to be mentioned that revision of the IACS scatter diagram is under discussion within the maritime industry.

In the design process, international standards are followed to calculate ship structural strength and ship stability during extreme events with a return period of 20/25 years; the Ultimate Limit State (ULS) check corresponding to the maximum load carrying resistance. Checks in the Accidental Limit State, ALS, (corresponding to the ability of the structure to resist accidental loads and to maintain integrity and performance due to local damage or flooding) cover grounding, collision, and fire and explosion. Extreme weather event check is not included in ALS.

Further, the shipping industry is commonly using the linear and non-linear regular waves and linear irregular waves as input to numerical codes for calculations of ship loads and responses. Use of the Pierson-Moskowitz spectrum (JONSWAP spectrum with the gamma spectral parameter $\gamma=1.0$ ) is recommended by IACS (2000). $\gamma=1.0$ is a stable configuration in terms of modulational instability (the mechanism responsible for generation of rogue waves), while $\gamma>$ 1 is more prone to modulational instability, provided a nonlinear wave model (third order or higher) is used to describe wave dynamics, see e.g., Bitner-Gregersen and Toffoli (2012). Modulation instability occurring in a steep sea state with a narrow wave spectrum will not be captured when $\gamma=1$ is assumed. This mechanism may have significant impact on local and 
global loads on ship structures as well as operational criteria; note that abnormal waves occur in low, intermediate and high sea states.

Figure 4 shows a wave bending moment for the LNG carrier investigated in EXTREME SEAS. The figure includes empirical data recorded in the TUB basin with rogue wave present, numerical simulations carried out by linear 3D Panel code with linear irregular wave input and 3D Panel code simulations with some non-linear correction but linear irregular wave input. As seen in Figure 7 impact of rogue waves on bending moment is significant.

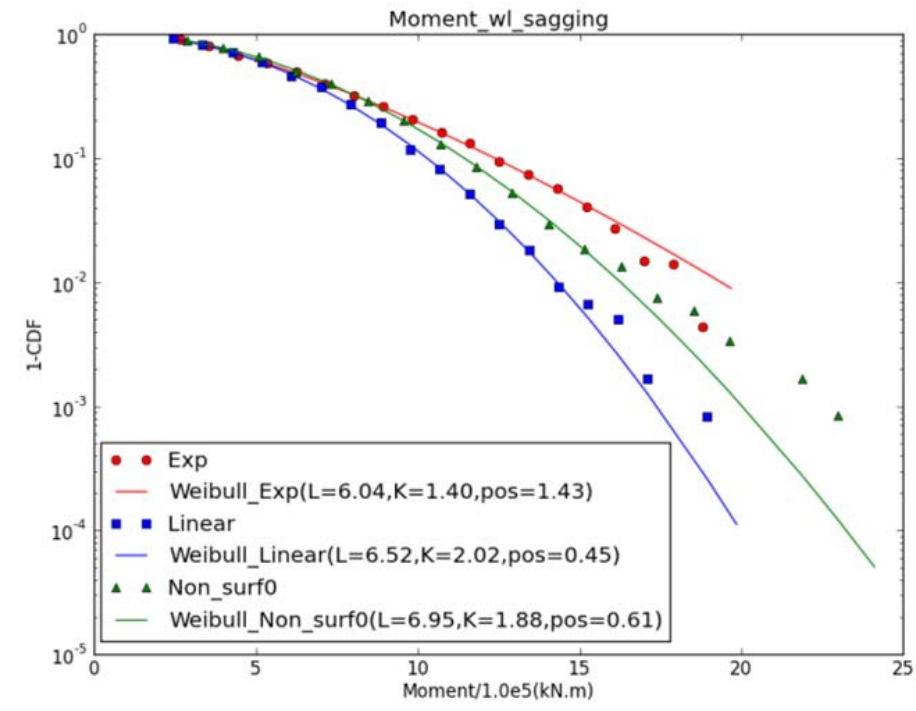

Fig. 7. Wave bending moment in rogue waves; experimental data, numerical simulations carried out by linear 3D panel code with the linear wave input and with some nonlinear corrections but linear irregular waves, after Guo et al. (2013).

Effect of ship forward speed on ship responses in abnormal waves is addressed by Bennet et al. (2013) and Guo and Bitner-Gregersen (2014). The latter study shows that ship motions are increased significantly by the slow forward speed.

Global warning due to human activities leads to changes in ocean environmental conditions, IPPC (2013). Observed and projected changes in waves and wind climate are expected to have the largest impact on marine structure design in comparison with other environmental 
phenomena. Bitner-Gregersen et al. (2013) show consequences of climate change on current design practice of tankers. They maybe significant if $H_{s}$ increases beyond $0.5 \mathrm{~m}$.

Lower and intermediate sea states which ships experience during their operations will be usually of combined nature including both wind sea and swell characterized by two peak spectrum, see Figure 5. Use of the PM spectrum does not account for it.



Fig. 5. Wave spectrum in the Haltenbanken location in the Norwegian Sea; measured data and the Torsethaugen spectrum.

Marine operations require more detailed description of sea state variability than long-term sea state distributions used for design can provide, e.g. optimal ship routing Mao et al. (2010a), estimation of variance in accumulated fatigue damage Mao et al. (2010b), construction of warning systems for high sea levels, extreme waves and planning of marine operations. These applications use correlations between sea state parameters at different locations and moments in time. Such information is often a part of spatio-temporal models of sea state variability. The manoeuvrability of ships in waves are more limited in coastal waters than in the open sea: while in the open sea, it is sufficient to keep a favourable heading with respect to wind and waves, in coastal waters, due to navigational restrictions, the ship might need to keep a 
prescribed track irrespective of the direction of waves and wind. On the other hand, ships are not supposed to be in coastal areas in very severe weather conditions, and should leave to the open sea before the weather conditions become too severe. Thus, the weather conditions used in the assessment procedure can be relaxed in comparison with the worst possible weather conditions expected in unrestricted service, see Papanikolaou et al. (2014).

In order to determine the adverse weather condition, comprehensive assessments were carried out using numerical simulations. North-Atlantic scatter table from IACS Recommendation 34 (IACS, 2000) was used as a seaway climate for comprehensive assessments. Moreover, JONSWAP sea spectrum with the peak parameter of 3.3 was considered for coastal waters. The results of the comprehensive assessments were compared with the results of the statistical approach (Level-1 assessment). Consequently, the adverse conditions used for Level-2 assessment were determined taking into consideration both results of the comprehensive assessments and the statistical approach (see IMO, 2013).

Hereafter, the adverse conditions specified in "2013 Interim Minimum Power Guidelines” (“Resolution MEPC.232(65)”; IMO, 2013) are validated by new research projects on the minimum propulsion power such as the EC project SHOPERA (Energy Efficient Safe SHip OPERAtion), (Papanikolaou et al., 2014) and a new Japanese R\&D project (MEPC67/INF.22, 2014).

\subsection{Offshore structures}

Offshore structures normally operate at fixed locations. As a result, platform design and operational conditions need to be based on location specific metocean climate. Note that Floating Production Storage and Offloading (FPSO) systems are designed for the North Atlantic wave environment if location specific wave climate cannot be proved more appropriate. 
Offshore structures (including FPSOs) follow a different approach to ship structures and are designed for the 100-year return period (ULS). The Norwegian offshore standards, being now under updating, (NORSOK, 2007) take into account extreme severe wave conditions by requiring that a 10000-year wave does not endanger the structure integrity (ALS). $2^{\text {nd }}$ order irregular waves are currently applied by the offshore industry when assessing structural loads and responses, see e.g. Stansberg (2012). Both linear and second order wave models are not able to capture very steep waves such as rogue waves.

The prediction of horizontal velocities underneath measured irregular wave surface elevations is of importance for assessment of loads on offshore structures and slamming problems. Birknes et al. (2013) addressed the topic using a simple case of unidirectional waves in deep water. The results from three commonly used methods for calculating the crest kinematics (two second order wave models and the Wheeler stretching, see DNV, 2014) are compared with the model test results. All three methods show a reasonable agreement with model tests although the second order models are clearly superior to the Wheeler method. However, when wave breaking is present the second order model is expected to underestimate the kinematics at the very top of the crest and the velocities can exceed the phase velocity. To obtain satisfactory prediction of wave kinematics higher order potential theory's solutions (e.g. HOSM, Toffoli et al., 2012) and CFD methods need still further exploration, particularly for very steep and breaking waves.

Very steep and breaking waves are getting growing attention in offshore industry because of their impact on loads and responses of offshore platforms. They have been addressed by the CresT (Buchner et al., 2011) and ShortCresT (Hening et al., 2015) projects, and in MARINTEK. In MARINTEK combination in a consistent manner of CFD and model tests has intensively been studied in the last years, e.g. Pakozgi et al. (2012), Stansberg et al. (2012). Commonly, extreme random wave events identified from numerical simulations or 
model tests are isolated and modelled by CFD, Stansberg et al. (2012), Henning et al. (2015). This methodology is under development and attention to it will grow in the future.

Uncertainties in long-term description of sea states $\left(H_{s}\right)$ may have major impact on the quality of fatigue life predictions, however uncertainty in the chosen power spectral densities is also of importance, Bengtsson et al. (2009).

There are several applications where development of more complex descriptions of sea states is needed, e.g. distributions of length of calm periods (offloading operations); prediction of time of occurrence of dangerous sea states, etc. For these applications models of evolution of sea states are needed. In addition to hindcasts and meteorological forecasts one may also use probabilistic models employing correlations between sea-state parameters in space and time, see Baxevani and Rychlik (2007), Podgórski and Rychlik (2014).

\section{Conclusions}

The review of some uncertainties associated with wave data and models defining sea state conditions currently used in design and operation procedures of ship and offshore structures and model testing is given. The study is addressing a wide ranging topics' area but due to limited space is not exhaustive. However, we believe that the reader will gain a fair and balanced view of the subjects covered.

The intention of the paper is to put again attention on uncertainties associated with wave description as this is an important input to assessment of loads and motions and fatigue damage of ships and offshore structures as well as to model testing. Several of these uncertainties still require further research and are not fully quantified herein. 
Effects of some of these uncertainties on assessment of loads and responses is demonstrated putting particular focus on very steep waves, their impact is significant. To be able to account for very steep waves in assessment of loads and responses of ship and offshore structures enhancement of currently used wave-structure interaction codes is necessary. Further, development of a consistent procedure for inclusion very steep waves in CFD calculations is called for.

The present study is not addressing smaller crafts and marine renewable energy structures as they were not a part of the scope of the $2^{\text {nd }}$ Joint ITTC-ISSC Workshop. However, the identified uncertainties related to the metocean description apply also to these structures. Use of renewable energy sources, especially offshore wind energy, is expected to increase in the future. The observed trends in the development of new sensors and data acquisition techniques for renewable energy sector is expected to continue. With the increase of offshore wind energy installations, reliable forecasts of the order of hours or minutes are also becoming increasingly important since the complex electrical networks are sensitive to large fluctuations, which may occur at the onset of a storm. In addition, more information on the wind profile in the lower atmospheric layer is needed for the design and analysis of these structures. Further, non-stationarity and non-homogeneity of the wind field needs to be accounted for.

Awareness of importance of accounting for uncertainties associated with environmental description in risk assessment of ship, offshore and renewable energy structures is continuously increasing within the marine and renewable energy industry. Although several data, statistical and model uncertainties have been reported during the period of the ISSC 2015 Committee I.1 a systematic investigation of them is still lacking. 


\section{Acknowledgement}

The authors would like to express their thanks to the 2015 Committee I.1 Liaison Prof. Carlos

Guedes Soares for following the Committee I.1. Particular thanks are addressed to Prof. Yonghwan Kim, the Chairman of ITTC Sea Keeping Committee for organization of the $2^{\text {nd }}$ Joint ITTC-ISSC Workshop and for supporting the study. The Committee would like also thanks Prof. Pandeli Temarel, the Chairman of ISSC 2015 I.2 (Loads) Committee, and Prof. Qiu Wei, the Chairman of ITTC Ocean Engineering Committee, for valuable discussions and collaboration.

\section{References}

Aarnes, O.J., Breivik, Ø., Reistad, M., 2011. Wave Extremes in the Northeast Atlantic. J. Climate, doi:10.1175/JCLI-D-11-00132.1

Anderson, C.W., Carter, D.J.T., and Cotton, P.D., 2001. Wave climate variability and impact on offshore design extremes. Shell International Report.

Ardhuin, F., Roland, A., Dumas, F., Bennis, A.C., Sentchev, A., Forget, P., Wolf, J., Girard, F., Osuna, P., Benoit, M., 2012. Numerical Wave Modeling in Conditions with Strong Currents: Dissipation, Refraction, and Relative Wind. Journal of Physical Oceanography, 42(12), 2101-2120. Publisher's official version :http://dx.doi.org/10.1175/JPO-D-110220.1

Baxevani, A., Rychlik, I., 2007. Fatigue Life Prediction for a Vessel Sailing the North Atlantic Route,Probabilistic Engineering Mechanics, 22, 159-169.

Baxevani A., Borgel C., Rychlik I., 2008. Spatial models for the variability of the significant wave height on the World Oceans. J. Offshore and Polar Engineering, 18, 1-17.

Bengtsson A., K., Bogsjø, K and Rychlik, I., 2009. Uncertainty of estimated rainflow damage for random loads, Marine Structures, 22, 261-274.

Bennett, S.S., Hudson, D.A., Temarel, P., (2013). The influence of forward speed on ship motions in abnormal waves: Experimental measurements and numerical predictions. Journal of Fluids and Structures 39, 154-172

Benoit, M., Frigaard, P., Schäffer, A., 1997. Analysing multidirectional wave spectra: a tentative classification of available methods, In: Proceedings of IAHR'97, seminar on multidirectional waves and their interaction with structures, San Francisco, 1997, 131158.

Birknes, J., Hagen, Ø., Johannessen, T.B., Nestegård, A., 2013. Second-Order Kinematics Underneath Irregular Waves. Proceedings OMAE 2013, Nantes, France, June 9-14.

Bitner-Gregersen, E. M. and Hagen, Ø., 1990. Uncertainties in Data for the Offshore Environment, Struct. Safety 7, 11-34, doi:10.1016/0167-4730(90)90010-M.

Bitner-Gregersen, E. M., Crame E. H., Korbijn F., 1995. Environmental description for longterm load response of ship structures. Proc. ISOPE 1995, Hague, The Netherlands, June 11-16. 
Bitner-Gregersen, E.M., Haver, S., Løseth, R., 1992. Ultimate limit states with combined load process. Proceedings of the $2^{\text {nd }}$ International Offshore and Polar Engineering Conference (ISOPE 1992), San Francisco, U.S., June 14-19.

Bitner-Gregersen, E.M., Hagen, Ø., 1999. Extreme value analysis of wave steepness and crest using joint environmental description. Proc. of the $18^{\text {th }}$ International Conference on Offshore Mechanics and Arctic Engineering (OMAE 1999), St. Johns, Newfoundland, Canada, July 11-16.

Bitner-Gregersen, E.M., 2012. Joint long-term models of met-ocean parameters, CENTEC Anniversary Book, CRC Press, Taylor and Francis, London, UK.

Bitner-Gregersen, E. M., Toffoli, A. 2012. On the probability of occurrence of rogue waves. Natural Hazards and Earth System Sciences, 12 , 751-762.

Bitner-Gregersen, E.M., Eide, L.I., Hørte, T., Skjong, R., 2013. Ship and Offshore Structure Design in Climate Change Perspective. Springer, Monograph. ISBN 978-3-642-34137-3.

Bitner-Gregersen, E. M., Bhattacharya, S. K., Chatjigeorgiou, Y. K., Eames. I., Ellermann, K., Ewans, K., Hermanski, G., Johnson, M. C., Ma, N., Maisondieu. C., Nilva, A., Rychlik. I., Waseda, T., 2014a. Recent developments of ocean environmental description with focus on uncertainties. Ocean Engineering, 86, 26-46.

Bitner-Gregersen, E. M., Ewans, K. C., Johnson, M. C. 2014b. Some uncertainties associated with wind and waves description and their importance for engineering applications. Ocean Engineering, 86, 11-25.

Bitner-Gregersen, E. M., Fernandez, L., Lefevre, J.-M., Toffoli, A. 2014c. The North Sea Andrea storm and numerical simulations. Natural Hazards and Earth System Sciences, 14, 1-9, doi:10.5194/nhess-14-1-2014

Bitner-Gregersen, E. M., Eide, L. I., Hørte, T., Vanem, E. 2014d. Impact of Climate Change and Extreme waves on Tanker Design. Proceedings of the SNAME Conference., Houston, USA, October 23-25.

Bitner-Gregersen, E.M., Toffoli, A., 2014. Probability of occurrence of rogue sea states and consequences for design of marine structures. Ocean Dynamics, ISSN 1616-7341, DOI 10.1007/ s10236-014-0753-2.

Bitner-Gregersen, E.M., Magnusson, A.K. 2014. Effect of intrinsic an sampling varaibility on wave parameters and wave statistics. Ocean Dynamics, 64 (11). 1643-1655, DOI: 10.1007/s10236-014-0768-8.

Bitner-Gregersen, E.M. 2015. Joint met-ocean description for design and operations of marine structures. Special Issue of Applied Ocean Research on the SAFE OFFLOAD project. http://dx.doi.org/10.1016/j.apor.2015.01.007

Bitner-Gregersen, E.M., Toffoli, A. 2015. Wave steepness and rogue waves in the changing climate in the North Atlantic. Procceedings of the OMAE 2015 Conference, St. John's, Newfoundland, Canada, May 31 - June 5

British Maritime Technology (BMT), 1986. (Primary Contributors: Hogben N., Da Cunha L.F., Oliver H.N.), Global Wave Statistics, Unwin Brothers Limited, London, England.

Boudiere, E., Maisondieu, C., Ardhuin, F., Accensi, M., Pineau-Guillou, L., Lepesqueur, J., 2013. A suitable metocean hindcast database for the design of Marine energy converters. International Journal of Marine Energy, 3-4, e40-e52. Publisher's official version : http://dx.doi.org/10.1016/j.ijome.2013.11.010, Open Access version: http://archimer.ifremer.fr/doc/00164/27524/

Buchner, B., Forristall G., Ewans, K.C., Christou, M., Hennig, J., 2011. New insights in extreme crest height distributions (a summary of the 'CREST' JIP). Proceedings OMAE 2011, Rotterdam, June 19-24. 
Cardone, V.J., Cox, A.T., 2011. Modelling very extreme sea states (VESS) in real and synthetic design level storms. Proceedings OMAE 2011, Rotterdam, The Netherlands, June19-24.

Cardone, V. J., Callahan, B.T., Chen, H., Cox, A.T., Morrone, M. A., Swail, V.R., 2014. Global distribution and risk to shipping of very extreme sea states (VESS). International Journal of Climatology, Published online in Wiley Online Library (wileyonlinelibrary.com) DOI: 10.1002/joc.3963 12th International Workshop on Wave Hindcasting and Coastal Hazards, Hawaii, USA, Nov. 2012.

Cartwright, D.E., Longuet-Higgins, M.S., 1956. Statistical distribution of the maxima of a random function. Proc., Roy. Soc. A, 237, 212-232.

Cavaleri, L, Alves, J.-H. G. M., Ardhuin, F., Babanin, A., Banner, M., Belibassakis, K., Benoit, M., Donelan, M., Groenweg, J, Herbers, T. H. C., Hwang, P., Janssen, P. A. E. M., Janssen, T., Lavrenov, I. V., Magne, R., Monbaliu, J., Onorato, M., Polnikov, V., Resion, D, Rogers, W. E., Sheremet, A., McKee Smith, J., Tolman, H. L., Van Vledder, G., Wolf, J. and Young, I., 2007. Wave modelling - the state of the art. Progress in Oceanography, 75:4, 603-674.

Cavaleri, L., Bertotti, L., Torrisi, L. Bitner-Gregersen, E., Serio, M., Onorato, M., 2012. Rogue waves in crossing seas: The Louis Majesty accident. J. Geophysical Research, 117, CXXXXX, doi:10.1029/2012JC007923.

Chawla, A., Spindler, D., Tolman, H.L., 2013. Validation of a thirty year hindcast using the climate forecast system reanalysis wind, Ocean Modeling 70, 189-206 http://dx.doi.org/10.1016/j.ocemod.2012.07.005

Christou, M., Ewans, K. 2014. Field measurements of rogue water waves. J. Phys. Oceanogr. doi:10.1175/JPO-D-13-0199.1

Clauss, G., Klein, M., Dudek, M., Onorato, M., 2012. Application of Breather Solutions for the Investigation of Wave/Structure Interaction in High Steep Waves. 31th OMAE International Conference on Ocean, Offshore and Arctic Engineering, Rio de Janeiro, Brazil, July 1-6.

Collard, F., Ardhuin, F., Chapron, B., 2005. Extraction of Coastal Ocean Wave Fields From SAR Images, IEEE JOURNAL OF OCEANIC ENGINEERING, 30 (3), July 2005, pp. 526-533.

Mc Combes, T, Johnstone, C., Holmes, B., Myers, L. E., Bahaj A.S., Heller, V. , Kofoed, J-P., Finn, J., Bittencour, C., 2010a. Assessment of current practice for tank testing of small marine energy devices. Equimar D3.3.

Mc Combes T, Johnstone C., Holmes B., Myers L. E., Bahaj A.S., Kofoed J-P., 2010b. Best practice for tank testing of small marine energy devices. Equimar D3.4.

CresT (Cooperative Research on Extreme Seas and their impact), Coordinated by MARIN, contact: B.Buchner@marin.nl, http://www.marin.nl/web/JIPs-Networks/Public/CresT.htm

Der Kiureghian, A., Liu, P. L., 1986. Structural reliability under incomplete reliability calculations. J. Eng.Mechanics ASCE, 112.

Didenkulova I., 2010. Shapes of freak waves in the coastal zone of the Baltic Sea (Tallinn Bay). Boreal Env. Res. 16. Suppl. A, 138-148. ISSN 1239-6095.

Didenkulova, I., Nikolkina, I., Pelinovsky, E., 2013. Rogue waves in the basin of intermediate depth and the possibility of their formation due to the modulational instability. JETP Letters 97, 194-198.

DNV, 2014. RP-C205. Environmental Conditions and Environmental Loads, DNV, 2014 (under updating).

Dong, S., Wang, L., Fu, X.-Y., 2007. Design parameter estimation under multivariate extreme ocean environmental conditions in the Bohai Sea. Proc. of International Conference on Ocean, Offshore and Arctic Engineering, 2007 San Diego, California, USA. 
Dong, S., Liu, W., Zhang, L., Guedes Soares, C., 2013a. Return value estimation of significant wave heights with maximum entropy distribution. Journal of Offshore Mechanics and Arctic Engineering ,135.

Dong, S., Tao, S.S., Lei, S.H., Guedes Soares, C. 2013b. Parameter estimation of the maximum entropy distribution of significant wave height. Journal of Coastal Research 29(3), 597604.

Dong, S., Wang, N.N., Liu, W., Guedes Soares, C. 2013c. Bivariate maximum entropy distribution of significant wave height and peak period. Ocean Engineering, 59(1), 86-99.

Dysthe, K., Trulsen, K., Krogstad, H. E., Socquet-Juglard, H., 2003. Evolution of a narrowband spectrum of random surface gravity waves. J. Fluid Mech., 478, 1-10.

Dysthe, K., Krogstad, H. E., Müller, P., 2008. Oceanic rogue waves. Annual Review of Fluid Mechanics 40, 287-310, doi:10.1146/annurev.fluid.40.111406.102203.

EXTREME SEAS, 2011. Design for Ship Safety in Extreme Seas. EC Grant agreement no.: 234175, Annex I, Description of Work, 7th FP. Coordinated by Legacy DNV, Norway.Contact: Elzbieta.Bitner-Gregersen@dnvgl.com, http://cordis.europa.eu/projects/ rcn/93940_en.html,http://cordis.europa.eu/projects/rcn/93940_en.html.

Ewans, K.C., 1998. Observations of directional spectrum of fetch-limited waves. Journal of Physical Oceanography, 28, pp. 495-512.

Ewans, K.C., Jonathan, P., 2014. Evaluating environmental joint extremes for the offshore industry. J. Marine Systems, 130, 124-130.

Feld, G., Randell, D., Wu, Y., Ewans, K.C., Jonathan.P., 2014. Estimation of storm peak and intra-storm directional-seasonal design conditions in the North Sea. Proc. 33nd Conf. Offshore Mech. Arct. Eng., San Francisco, USA, June 7-14.

Jonathan, P., Randell, D., Wu, Y., Ewans, K., 2014. Return level estimation from non-stationary spatial data exhibiting multidimensional covariate effects. Ocean Eng.

Forristall, G.Z., Ewans, K., Olagnon, M., Prevosto, M., 2013. The WesT Africa Swell Project (WASP). Proceedings of the OMAE 2013 Conference, 9-14 June 2013 Nantes, France.

Fu, T.C., Fullerton, A. M., Hackett, E.E., Merrill, C., 2011. Shipboard Measurement of Ocean Waves. Proc. OMAE 2010, Shanghai, China.” to “ Fu T. C., Fullerton A. M., Hackett, E. E., and Merrill C. (2011). Shipboard measurement of ocean waves. Proceedings of OMAE 2011 Conference, Rotterdam, The Netherlands, June 19-24.

Guedes Soares, C., 1984. Representation of double-peaked sea wave spectra. Ocean Engineering, 11, 185-207.

Guo, B.J., Bitner-Gregersen, E. M., Sun, H, Helmers, J.B., 2013. Prediction of Ship Response Statistics in Extreme Seas Using Model test data and Numerical Simulation based on the Rankine Panel Method, Proceedings of the 29th International Conference on Ocean, Offshore and Arctic Engineering, OMAE 2013 (OMAE2013-10351), Nantes, France, June 7-14.

Guo, B., Bitner-Gregersen, E.M., 2014. Effect of ship forward speed on ship response statistics in extreme seas. Proc. OMAE 2014 Conf. OMAE2014-24695, June 8 - 13, 2014, San Francisco, California, U.S.

Hagen, Ø., Falkenberg E., Bitner-Gregersen, E.M., 2015. Reliability Based Approach for Offloading Operation Related to Motion of Two Side-by-Side Moored LNG Carries. Special Issue of AOR.

Haver, S., Anderson, O.J., 2000. Freak waves: Rare realizations of a typical population or typical realizations of a rare population. Proceedings of the $10^{\text {th }}$ International Offshore and Polar Engineering (ISOPE) Conference, Seattle, USA, May 28-June 2.

Haslett, S. K., Bryant, E. A., 2009. Meteorological Tsunamis in Southern Britain : An Historical Review, Geographical Review, 99, 2, 146-163. 
Hennig, J., Scharnke, J., Swan, C., Hagen, Ø., Ewans, K., Tromans, P., Forristall, G.Z., 2015. Effects of short-crestedness on extreme wave impact - A summarey of findings from the Joint Industry project ShortCresT. Proceedings of the OMAE 2015 Conference, St. John's, Newfoundland, Canada, May 31 - June 5.

Hirdaris, S., 2014. Special Issue on Uncertainty Modelling for Ships and Offshore Structures, Ocean Engineering. Editorial Note, 86, 1, 1-2, August 2014.

Hu H., Ma N., Wang X., Gu X., 2010a. Numerical Simulations of Rogue Waves for Experimental Investigation Based on the Fourth-order NLS Equation, Proc. OMAE 2009, Hawaii, USA. 2, 269-278.

Hu H. and Ma N., 2010b. The Nonlinear Evolution of Rogue Waves Generated by Means of Wave Focusing Technique, Science China. Series G., 54(1), 1-7.

Hu H. and Ma N., 2011. Numerical Simulation on Nonlinear Evolution of Rogue Waves on Currents based on the NLS Equations, Proc. OMAE 2011, Rotterdam, NL, June 19-24.

IACS, 2000. Standard Wave Data. IACS Rec. 34. Rev.1, Corrected Nov. 2001.

IMO 2013. 2013 Interim guidelines for determining minimum propulsion power to maintain the manoeuvrability in adverse conditions. Resolution MEPC.232(65).

IPPC, 2013. The Fifth Assessment Report: Climate Change (AR5): The AR5 Synthesis Report. AR5. UN.

ISSC, 2009. ISSC 2009 Committee I.1 Environment Report. Proc. ISSC 2009, 1, 1-126, Seoul, Korea.

ISSC, 2012. ISSC 2012 Committee I.1 Environment Report. Proc. ISSC 2012, 1, 1-78, Rostock, Germany.

ISSC, 2013. Reply to the Official Discusser, ISSC 2012 Committee I.1 Environment. Proc. ISSC 2012, Vol.III, Rostock, Germany.

ISSC, 2015. ISSC 2015 Committee I.1 Environment Report. Proc. ISSC 2015, 1, Lisbon, Portugal.

Johnson, M.C., 2004. Improvements in the conduct and interpretation of ship seakeeping trials. Ph.D. thesis, University of Southampton, 2004

Kahma K., Hauser D., Krogstad H.E., Lehner S., Monbaliu J.A.J., Wyatt, L.R., 2005, Measuring and Analysing Directional Spectra of Ocean Waves, EU COAST Action 714, EUR 21367, ISBN 92-898-0003-8

Kitaigorodskii, S.A., 1983. On the theory of the equilibrium range in the spectrum of windgenerated gravity waves. J. Phys. Oceanogr. 13, 816-827, http://dx.doi. org/10.1175/1520-0485(1983)013o0816:OTTOTE42.0.CO;2.

Kpogo-Nuwoklo, K.A., Olagnon, M., Guédé, Z., 2014. Wave spectra partitioning and identification of wind sea and swell events. Proceedings of the OMAE 2014 Conference, San Francisco, California, USA, June 8-13.

Krogstad, H.E., Barstow, S.F., Haug, O., Peters., D.J.H., 2004. Directional distributions in wave spectra, In: Proceedings of Ocean Wave Measurements and Analysis Conference, 2004, 883-895.

Lindgren, G., Prevosto, M., 2015. Wafol - a Wave module for Analysis of Random Lagrange Waves. Tutorial for Wafol Version 1.2, Lund Dec. 2015.

Longuet-Higgins, M.S., 1976. On the nonlinear transfer of energy in the peak of a gravity-wave spectrum: a simplified model. Proceedings of the Royal Society of London, Sect. A., 347, 311-328.

Ma, Y., Dong, G., Ma, X. Investigations of the Effetcs on Benjamin-Feir Instability by Uniform Currents. 33nd International Conference on Ocean, Offshore and Arctic Engineering, Nantes, France, June 9-14 June.

Madsen, H.O., Krenk, S. and Lind, N.C., 1986. Methods of Structural Safety. Prentice-Hall, Enlewood Cliffs, NJ 07632. 
Magnusson, A.K., Donelan, M.A., 2013. The Andrea wave. Characteristics of a measured North Sea rogue wave. JOMAE, 1(2013) March 13, doi:10.1115/1.4023800

Maisondieu, C., Le Boulluec, M., 2015. Benefits of using a spectral hindcast database for wave power extraction assessment, OWEMES 8th ed., 93-96.

Mao, W., Rychlik, I., Storhaug, G., 2010a. Safety index of fatigue failure for ship structure details, Journal of Ship Research 54 (3), 197-208.

Mao, W., Ringsberg, J., Rychlik, I., 2010b. Development of a fatigue model useful in ship routing design. Journal of Ship Research 54 (4), 281-293.

Mao, W., Rychlik, I., 2012. Extreme estimation of ship response. Journal of Ship Research 56(1):23-34. DOI:10.5957/JOSR.56.1.100032

Mc Combes, T, Johnstone, C., Holmes, B., Myers, L. E., Bahaj A.S., Heller, V. , Kofoed, J-P., Finn, J., Bittencour, C., 2010a Assessment of current practice for tank testing of small marine energy devices. Equimar D3.3.

Mc Combes T, Johnstone C., Holmes B., Myers L. E., Bahaj A.S., Kofoed J-P., 2010b. Best practice for tank testing of small marine energy devices. Equimar D3.4.

Monserrat, S., Vilibić, I., and Rabinovich, A. B., 2006. Meteotsunamis : atmospherically induced destructive ocean waves in the tsunami frequency band, Nat. Hazards Earth Syst. Sci., 6, 1035-1051.

Nataf, A. 1962. Determination des Distribution dont les Marges sont Donnees, Comptes Rendus l'Academie des Sciences, 225, 42-43, Paris, France.

Nielsen, U. D., Stredulinsky, D. C. 2012. Sea state estimation from an advancing ship - A comparative study using sea trial data. Applied Ocean Research 34, 33-44

Nikolkina, I., Didenkulova, I. 2012. Catalogue of rogue waves reported in media in 2006-2010. Nat. Hazards Earth Syst. Sci., 61.

NORSOK, 2007. Standard N-003: Action and action effects, Rev. 2. http://www.standard.no /pronorm-3/data/f/0/03/78/7_10704_0/N-003d2r2.pdf (under revision).

Onorato M., Osborne A.R., Serio M., Cavaleri L., Brandini C., and Stansberg C. T., 2004. Observation of strongly non-Gaussian statistics for random sea surface gravity waves in wave flume experiments. Phys. Rev. E 70, 067302

Onorato, M., Osborne, A., Serio, M., Cavaleri, L., Brandini, C., Stansberg, C., 2006a. Extreme waves, modulational instability and second order theory: wave flume experiments on irregular waves. European Journal of Mechanics - B/Fluids 25, 86-601.

Onorato, M., Osborne, A., Serio, M., 2006b. Modulation instability in crossing sea states: a possible mechanism for the formation of freak waves. Phys Rev Lett 96:014503. doi:10.1103/PhysRevLett.96. 014503

Ochi, M. K., Hubble, E.N.,1976. On six-parameters wave Spectra. Proceedings of 15th Coastal Engineering Conference, 1976, 301-328.

Olagnon M., Guédé Z., 2010. Parametric Rainflow Fatigue Damage for Some Power Spectra of Common Use, Proc. OMAE 2010, Shanghai, China. 2, 101-107. Osborne, A., 2010. Nonlinear ocean waves and the inverse scattering transform. Academic Press, 2010, ISBN: 978-0-12-528629-9, 944 pp.

Osborne, A., 2013. Classification of Rogue Wave Solutions of the Nonlinear Schroedinger Equation. EGU General Assembly Geophysical Research 2013, NH5.2. Vienna, Austria.

Papanikolaou, A., Zaraphonitis, G., Bitner-Gregersen, E., Shigunov, V., El Moctar, O., Guedes Soares, C., Reddy, D. N., Sprenger, F., 2014. Energy Efficient Safe Ship Operation (SHOPERA). Proceedings RINA Conference, London, UK, Sept. 24-25.

Philips, O.M., 1958. The equilibrium range in the spectrum of wind-generated waves. J. Fluid Mech. 4, 426-434.

Philips, O.M., 1985. Spectral and statistical properties of the equilibrium range in the windgenerated gravity waves. J. Fluid Mech. 156, 505-531. 
Pierson Jr., W.J., Moskowitz, L., 1964. A proposed spectral form for fully developed Wind Seas based on the Similarity Theory of S.A. Kitaigoradskii. J. Geophys. Res. 69, 51815190.

Podgórski, K. and Rychlik, I., 2014. A model of significant wave height for reliability assessment of a ship, Journal of Marine Systems, 130, 109-123.

Prevosto, M., Krogstad, H.E., Robin, A., 2000. Probability distribution for maximum wave and crest heights. Coastal Engineering 40, 329-360.

Queffeulou, P., 2013. Merged Altimeter Wave Height Database.An Update. Proc. 'ESA Living Planet Symposium 2013’, Edinburgh, UK9-13 September (ESA SP-722, December 2013.

Qiu, W., Sales, J. Junior, Lee, D., Lie, H., Magarovskii, V., Mikami, T., Rousset, J-M., Sphaier, S., Tao, L., Wang, X.. 2014. Uncertainties related to predictions of loads and responses for ocean and offshore structures, Ocean Engineering, 1 August, 2014, 1, 58-67, ISSN 00298018, http://dx.doi.org/10.1016/j.oceaneng.2014.02.031.

Rascle N., Ardhuin F., 2013. A global wave parameter database for geophysical applications. Part 2: Model validation with improved source term parameterization. Ocean Modelling, 70 (2013) 174-188, http://dx.doi.org/10.1016/j.ocemod.2012.12.001

Roland, A., Ardhuin, F., 2014. On the developments of spectral wave models: numeric and parameterization for the coastal ocean, Ocean Dynamics, 64:833-846 DOI 10.1007/s10236-014-0711-z

Rychlik, I., Rydẻn, J., Anderson, C.W., 2011. Estimation of return values for significant wave height from satellite data. Extremes 14 (2), 167-186.

Schäffer, H.A., Steenberg, C.M., 2003. Second-order wavemaker theory for multidirectional waves, Ocean Engineering 30, 1203-123, doi:10.1016/S0029-8018(02)00100-2

Stansberg, C.T., 2012. Analysis of Random Waves in Ocean Engineering., in Marine Technology and Engineering, Ed. Carlos G. Soares, Balkema/Taylor and Francis, The Netherlands.

Stansberg, C. T., Berget, K., Graczyk, M., Muthanna, C. \& Pakozdi, C., 2012. Breaking wave kinematics and resulting slamming pressures on a vertical column. Proceedings of the OMAE 2012 Conference, 1-6 July 2012, Rio de Janeiro, Brazil.

Saulnier, J.B., Prevosto, M., Maisondieu, C., 2011. Refinements of sea state statistics for marine renewables: A case study from simultaneous buoy measurements in Portugal. Renewable Energy, 36(11), 2853-2865. Publisher's official version : http://dx.doi.org/10.1016/ j.renene.2011.04.015, Open Access version : http://archimer.ifremer.fr/doc/00037/14813/

Tao, S. S., Dong, S., Wang, N. N., Guedes Soares, C. 2013a. Estimation storm surge intensity with Poisson bivariate maximum entropy distribution based on copulas. Natural Hazards, 68.

Tao, S. S., Dong, S., Xu, Y. H., 2013b. Design parameter estimation of wave height and wind speed with bivariate copulas. The Proceedings of 32nd International Conference on Offshore Mechanics and Polar Engineering, 9-14 June 2013 Nanes, France.

Toffoli, A., Onorato, M., Bitner-Gregersen, E., Monbaliu, J., 2010. Development of a Bimodal Structure in Ocean Wave Spectra. J. Geophys. Res., 115, C03006.

Toffoli A., Bitner-Gregersen E.M. 2011. Extreme and rogue waves in directional wave field. The Open Ocean Engineering Journal, 2011, 4, 24-33.

Toffoli, A., Bitner-Gregersen, E. M. \& Onorato, M., 2012. Statistics of wave orbital velocity in deep water random directional wave fields. Proceedings of the OMAE 2012 Conference, Rio de Janeiro, Brazil, July 2-6 July.

Toffoli, A., Fernandez, L., Monbaliu, J., Benoit, M., Gagnaire-Renou, E., Lefevre, J.M., Cavaleri, L., Proment, D., Pakozdi, C., Stansberg, C.T., Waseda, T., Onorato, M., 2013. Experimental evidence of the modulation of a plane wave to oblique 
perturbations and generation of rogue wavse in finite water depth. Physics of Fluids, 25, 091701.

Torsethaugen, K. A two-peak wave spectral model. Proceedings of the 12th International Conference on Offshore Mechanics and Arctic Engineering (OMAE 1993), Glasgow, UK, June 20-24.

Torsethaugen, K. 1996. Model for Double Peaked Wave Spectrum. SINTEF Civil and Environmental Engineering. Trondheim, Norway.

Waseda, T., Kinoshita, T., Tamura, H., 2009a. Interplay of resonant and quasi-resonant interaction of the directional ocean waves. Journal of Physical Oceanography 39(9), 2351-2362.

Waseda, T., Kinoshita, T., Tamura, H., 2009b. Evolution of a random directional wave and freak wave occurrence. Journal of Physical Oceanography 39(3), 621-639.

Waseda, T., Hallerstig, M., Ozaki, K. \& Tomita, H. 2011. Enhanced freak wave occurrence with narrow directional spectrum in the North Sea. Geophysical Research Letters, 38.

Waseda, T., Sinchi, M., Kiyomatsu, K., Nishida, K., Takahashi, S., Asaumi, S., Kawai, Y., Tamura, H. \& Miyazawa, Y. 2014. Deep water observations of extreme waves with moored and free GPS buoys. Ocean Dynamics, 64, 1269-1280 .

Wyatt, L. R., Green, J., Middleditch, A., 2011 HF Radar Data Quality Requirements for Wave Measurement, Costal Engineering, 58 (4), 327-336.

WMO 2001. Guide to Marine Meteorological Services. Geneva, Switzerland: World Meteorological Organization.

WMO 2003. Manual on the Global Observing System. Geneva, Switzerland: World Meteorological Organization.

Young, I. R., Babanin, A. V., Zieger, S., 2013. The decay rate of ocean swell observed by altimeter. Journal of Physical Oceanography, 43, 2322-2333. 